\title{
Blood Metabolic and Hematology Parameters and Survivorship in Mice after Application of the Rabies Challenge Virus Standard in Vaccine Potency Test
}

\author{
Nemanja Obradović', Branislava Belić2 , Marko Cincović', Dragana Vujin', \\ Aleksandar Potkonjak², Dragica Stojanović², Slavča Hristov ${ }^{3}$ \& Ivana Lakić
}

\begin{abstract}
Background: Rabies virus can cause intensive and lethal infection of the central nervous system (CNS) in animals and humans. Metabolic examinations are conducted at the cerebrospinal fluid (CSF), and it has been found that many metabolic changes occur during RABV infection. However, although it is a neurotropic virus, it can cause damage to extraneural tissues - lungs, heart, kidneys and liver. This study aimed to determine differences in metabolic, endocrinology and hematologic parameters in blood of mice after application of rabies challenge with virus standard 27 strain (CVS-27).

Materials, Methods \& Results: This study included 30 survived, and 30 dead mice that were part of the standard procedure of NIH (National Institute of Health) test in Pasteur Institute in Novi Sad. Tests were performed in the following order: two groups of mice were vaccinated in a 7 day period with different dilutions of standard vaccine and the examined vaccine. Seven days after the last vaccination, immunized animals and animals in the control group received test virus CVS-27. Blood samples were collected from a heart puncture. Differences in hematologic and biochemical parameters were determined by t-test. Due to a high number of blood parameters, we performed a joint analysis of multiple dependent variables. Higher $\mathrm{pH}$ value and higher concentrations of glucose, cholesterol, lactate dehydrogenase (LDH), creatine kinase (CK), albumin, urea, creatinine, $\alpha$-amylase, magnesium (Mg), nonesterified fatty acids (NEFA), beta-hydroxybutyrate (BHB) and lactate were noted in dead mice. Higher granulocytes and mean platelet volume (MPV) were noted in mice which died, but also reduced lymphocytes, erythrocytes, haemoglobin, hematocrit and platelets count. Higher values of insulin, cortisol and HOMA-IR (homeostatic model assessment insulin resistance) were noted in the group of dead mice compared to the surviving one. Reduced QUICKI (quantitative insulin sensitivity check index) value was noted in mice which died compared to the surviving group. Principal component analysis (PCA) showed that components 1 and 2 explain 38.7 of variance and that these two compounds are enough for the distinction between the animals which dies and those that survived. It was found that the cortisol, insulin, HOMAIR, NEFA, aspartate aminotransferase (AST), lactic acid, LDH and granulocyte could explain the variance of the first component, which highly correlated with the first principal component. Also, $\mathrm{pH}$ level, glucose, creatinine, albumin and BHB showed significant importance. A positive correlation was shown between those parameters.

Discussion: Mice that died during NIH test after applying CVS-27 expressed more significant stress (higher cortisol level). Disturbances of energy metabolism were noted (more significant catabolism of lipids and insulin resistance), changes of protein metabolism caused by muscle load (urea, creatinine, AST and LDH) and general disturbances of acid-base status (higher $\mathrm{pH}$ ) and dehydration (increased albumin) were also noted in mice that died. Values of hematologic parameters showed minor influence at total variability and are a bit correlated with metabolic changes. In factor analysis, component 1 was determined from numerous parameters. Correlations between component 1 and cortisol, HOMA-IR, lactates, insulin, AST and LDH were noted. It completely determines survived and dead animals after CVS-27 during NIH test. Disturbances in blood parameters showed an analogy with previous studies of CNS. Given parameters can be very useful in clinical-pathological analysis in RABV infection.
\end{abstract}

Keywords: mice, rabies virus, blood metabolite.

DOI: $10.22456 / 1679-9216.111103$ 


\section{INTRODUCTION}

Rabies virus (Family of Rhabdoviridae, Genus Lyssavirus) causes highly intensive and lethal infections in people and animals. It is a neurotropic virus with a high affinity for cell receptors, cytoplasm and transports across interneuronal synapses [8]. Rabies virus causes fatal encephalitis followed by a response of other organ systems. RABV stimulates immunologic response [3, 22], but there are no great pathologic changes in CNS and immunological clearance of RABV. The main cause of the lethal effect is the inhibition of the synthesis of proteins that showed a crucial role in cell metabolic functions [9]. Previous results showed significant metabolic changes in cerebrospinal fluid (CSF) during viral infection [32-34]. Metabolomic methods of CSF showed the occurrence of ketosis, while in later stages, there were changes in protein metabolism and cytotoxicity [21]. Differences in gene expression and domination of anaerobic metabolism in CNS during RABV infection were confirmed [23]. Even though the Rabies virus is neurotropic, some research showed that it could cause changes in many other tissues - lungs, heart, liver and kidneys [16]. Those results showed that macrophages are very significant in extraneural viral dissemination. Also, systemic response to RABV infection includes greater blood corticosterone concentrations [26] or systemic metabolic adaptations like keto-alkalosis to be found [7].

This study aims to determine differences in the systemic response of metabolic, endocrine and hematologic parameters in blood of mice that survived and not survived the standard National Institutes of Health (NIH) test [15] and the application of challenge virus standard 27 strain (CVS-27).

\section{MATERIALS AND METHODS}

\section{Animals and treatment}

The study included 30 mice that survived and 30 that did not. The study was conducted at Pasteur Institute in Novi Sad. The level of protection that is induced by the inactivated vaccine was determined by test. NIH test was performed on 2 mice groups at an interval of 7 days, with different standard and vaccine solutions. Seven days after the last vaccination, animals from the immunized and the control group received a test virus (Challenge Virus Standard, strain CVS-27) ${ }^{1}$ Mice $^{2}$ (white mice, strain Naval Medical Research Institute-NMRI) were supervised in the period of 14 days and mean effective dose (ED50) was determined according to the number of surviving animals. Before the test, animals were selected so that all animals included in the experiment were at least 4-week-old, 23-27 g weight and in good health condition. Before intracerebral inoculation of CVS-27 virus, in order to perform NIH test, animals were anaesthetized and treated with antibiotics administered intraperitoneally (the anaesthetic solution contained $1 \%$ ketamine and $0.1 \%$ xylazine diluted with sterile $0.01 \mathrm{~mol} / \mathrm{L}$ PBS and antibiotics). ${ }^{3}$ The amount of anaesthetic dilution per mouse was $0.3 \mathrm{~mL}$. The anaesthetic solution included $0.1 \mathrm{~mL}$ per $10 \mathrm{~g}$ of body weight. After $3 \mathrm{~min}$, every mouse received $0.05 \mathrm{~mL} / 10 \mathrm{~g} \mathrm{BW}$ of anaesthetic solution, and this was repeated until animals were fully anaesthetized. During full anaesthesia of mice, CVS-27 was administered intracerebrally. Mice were placed in cages in lateral positions in a dark room. The complete clinical exam should be performed before inoculation. Animals who expressed difficulties in motion, ectoparasites, and changes in fur or diarrhoea were excluded from the study.

\section{Blood parameters}

Blood samples were collected by heart puncture in appropriate tubes. ${ }^{4}$ Individual blood samples were taken after terminal anaesthesia on animals that survived at the end of the experiment. $\mathrm{pH}$ level was determined by $\mathrm{pH}$-meter. ${ }^{5}$ Hematologic parameters were determined by automatic analyzer ${ }^{6}$ using software for lab mice. Biochemical parameters were measured by standard reagents ${ }^{7}$ at automatic spectrophotometer ${ }^{8}$. Insulin and cortisol concentration were measured by automatic endocrinology analyzer ${ }^{9}$. Insulin resistance indexes QUICKI, HOMA- $\beta$ and HOMA-IR were determined according to formulas for lab mice [2].

\section{Statistical analysis}

Differences in values of hematologic and biochemical parameters were determined by $t$-test. Due to a high number of blood parameters, we performed a joint analysis of multiple dependent variables. Different metabolite levels in mice that survived and died after rabies virus challenge were illustrated by heatmap. The development of class model based on blood parameters as a predictor of survivorship in mice after rabies virus challenge in NIH test was performed by principal component analysis (PCA) with score plot and loading plot presentation. Statistical software ${ }^{10}$ SPSS (USA) and online platform ${ }^{11}$ were used for analysis and results representation. 


\section{RESULTS}

Significant differences in values of haematological, biochemical and endocrine parameters were determined in mice that died after RCVS application during NIH test compared to the control group (Table 1). Higher levels of glucose, cholesterol, LDH, CK, albumin, urea, creatinine, lactate, amylase, $\mathrm{Mg}$, NEFA, BHB and higher $\mathrm{pH}$ value were determined in dead mice. Greater neutrophil count and MPV, and reduced lymphocytes, erythrocytes, haemoglobin, hematocrit and platelets were found in dead animals. Endocrine changes in dead animals compared to control were: higher insulin, cortisol and HOMA-IR index, while QUICKI was reduced. No significant deviation of other parameters was noted.

The magnitude of the change in lab parameters is shown at the heat map (Figure 1). The heat map of the changes in metabolites related to survivorship of mice - blue colour represents the trend of decrease, and red represents a rising trend. The heat map shows differences in expression of numerous parameters in mice that survived and died, but some of the parameters do not express this when considered for each animal itself (MCV, P, Mg, Ca, WBC, TBil, PLT).

Principal component analysis (PCA) shows that component 1 and 2 explain $38.7 \%$ of the variance and that these two components are enough for proper discrimination of mice that died and survived (Figure 2). It shows that survivorship could be classified by PCA scores, and discrimination is mainly determined by the $\mathrm{X}$-axis (PC1).

As shown in Figure 3, the two axes represent the first 2 components, namely component 1 and component 2. It was found that cortisol, insulin, HOMA-IR, NEFA, AST, lactic acid, LDH and granulocyte could explain the variance of the first component, and highly correlated with the first principal component (major distance from the intersection point of two lines that pass 0 at $\mathrm{X}$ and Y-axis). Minor compared to this, but still, significant influence has $\mathrm{pH}$, glucose, creatinine, albumin and BHB (minor distance from the intersection point). These parameters show a positive correlation that can be reflected in a sharp angle whose top is the intersection point of lines that pass thru 0 and arms pass dots of examined parameters.

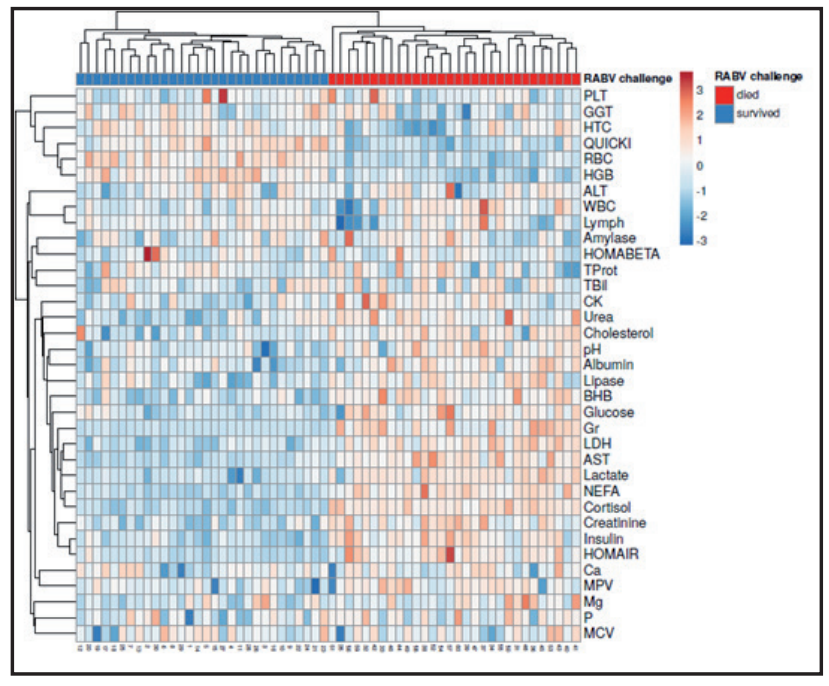

Figure 1. Heat map of expression of blood parameters in dead and surviving mice after RABV challenge (aplication of CSV-27).

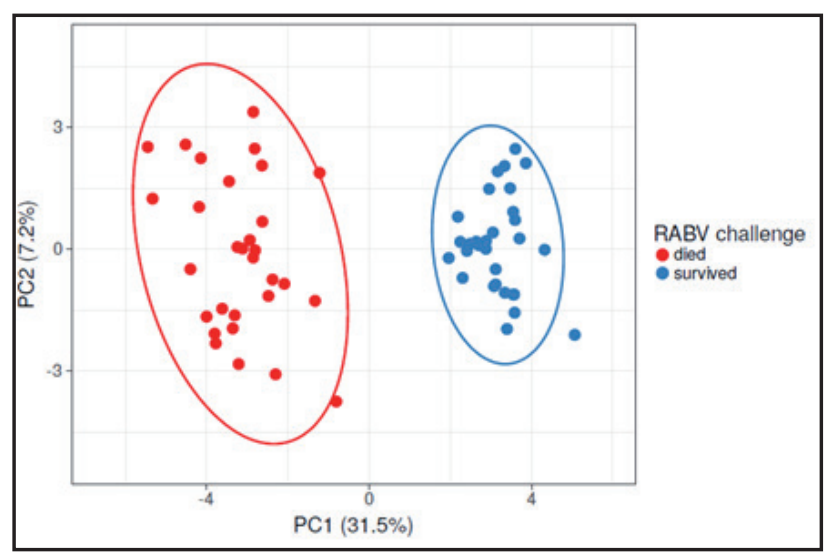

Figure 2. Principal component analysis and classification of died and survived mice after RABV challenge (aplication of CSV-27) in accordance to principal component 1 and 2 (PC1 and PC2).

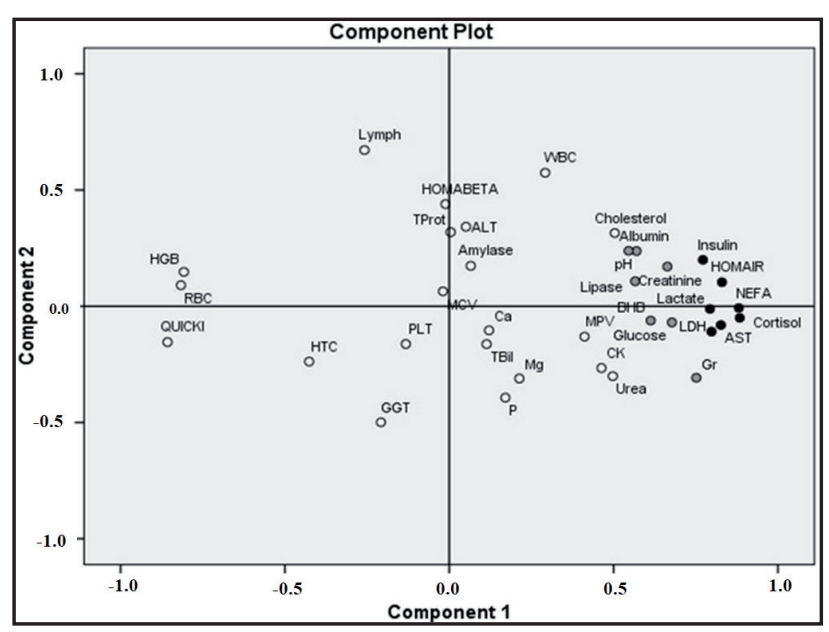

Figure 3. Biplot of component coefficients for each blood variable. 
N. Obradović, B. Belić, M. Cincović, et al. 2021. Blood Metabolic and Hematology Parameters and Survivorship in Mice after Application of the Rabies Challenge Virus Standard in Vaccine Potency Test. ActaScientiae Veterinariae.49: 1794.

Table 1. Blood parameters in died and survived mice after aplication of rabies virus standard challenge (CVS-27).

\begin{tabular}{|c|c|c|c|c|c|}
\hline \multirow{2}{*}{ Blood parameter } & \multicolumn{2}{|c|}{ Survived } & \multicolumn{2}{|c|}{ Died } & \multirow{2}{*}{ Significance } \\
\hline & Mean & SD & Mean & SD & \\
\hline $\mathrm{pH}$ & 7.36 & 0.08 & 7.47 & 0.08 & $P<0.01$ \\
\hline Glucose (mmol/L) & 8.82 & 1.38 & 11.30 & 2.27 & $P<0.01$ \\
\hline Cholesterol (mmol/L) & 2.69 & 0.27 & 2.99 & 0.27 & $P<0.01$ \\
\hline LDH (IU/L) & 542.50 & 87.90 & 782.59 & 108.31 & $P<0.01$ \\
\hline AST (IU/L) & 89.23 & 15.74 & 163.33 & 34.49 & $P<0.01$ \\
\hline CK(IU/L) & 89.23 & 15.76 & 106.19 & 18.76 & $P<0.01$ \\
\hline Urea $(\mathrm{mmol} / \mathrm{L})$ & 7.48 & 0.66 & 8.30 & 0.67 & $P<0.01$ \\
\hline Creatinine $(\mu \mathrm{mol} / \mathrm{L})$ & 27.15 & 2.54 & 31.50 & 2.94 & $P<0.01$ \\
\hline Lactate $(\mathrm{mmol} / \mathrm{L})$ & 4.50 & 0.39 & 5.49 & 0.48 & $P<0.01$ \\
\hline NEFA (mmol/L) & 0.13 & 0.04 & 0.35 & 0.08 & $P<0.01$ \\
\hline $\mathrm{BHB}(\mathrm{mmol} / \mathrm{L})$ & 0.28 & 0.10 & 0.45 & 0.10 & $P<0.01$ \\
\hline Albumin (g/L) & 26.40 & 2.84 & 29.66 & 2.66 & $P<0.01$ \\
\hline TProt $(\mathrm{g} / \mathrm{L})$ & 47.91 & 3.92 & 47.91 & 5.55 & NS \\
\hline $\mathrm{Ca}(\mathrm{mmol} / \mathrm{L})$ & 2.51 & 0.20 & 2.54 & 0.21 & NS \\
\hline $\mathrm{P}(\mathrm{mmol} / \mathrm{L})$ & 3.09 & 0.25 & 3.20 & 0.22 & NS \\
\hline $\mathrm{Mg}(\mathrm{mmol} / \mathrm{L})$ & 0.55 & 0.06 & 0.58 & 0.06 & $P<0.05$ \\
\hline ALT (IU/L) & 35.27 & 3.50 & 35.70 & 3.89 & NS \\
\hline GGT (IU/L) & 5.28 & 0.45 & 5.07 & 0.51 & NS \\
\hline TBil $(\mu \mathrm{mol} / \mathrm{L})$ & 3.89 & 0.68 & 4.04 & 0.71 & NS \\
\hline Amylase (IU/L) & 917.33 & 99.19 & 922.07 & 103.96 & NS \\
\hline Lipase (IU/L) & 83.39 & 9.02 & 93.90 & 8.34 & $P<0.01$ \\
\hline $\mathrm{WBC}\left(\times 10^{9} / \mathrm{L}\right)$ & 15.45 & 1.10 & 16.25 & 2.12 & NS \\
\hline $\operatorname{Gr}\left(\times 10^{9} / \mathrm{L}\right)$ & 2.10 & 0.18 & 4.18 & 1.29 & $P<0.01$ \\
\hline Lymph $\left(\times 10^{9} / \mathrm{L}\right)$ & 13.35 & 1.04 & 12.07 & 2.67 & $P<0.05$ \\
\hline $\mathrm{RBC}\left(\times 10^{12} / \mathrm{L}\right)$ & 12.41 & 1.47 & 8.81 & 1.04 & $P<0.01$ \\
\hline Hemoglobin (g/L) & 165.37 & 7.97 & 145.52 & 7.02 & $P<0.01$ \\
\hline MPV (fL) & 4.71 & 0.57 & 5.24 & 0.64 & $P<0.01$ \\
\hline Hematocrit HTC (\%) & 43.55 & 1.35 & 41.98 & 2.27 & $P<0.01$ \\
\hline $\mathrm{MCV}(\mathrm{fL})$ & 45.08 & 0.97 & 45.08 & 0.97 & NS \\
\hline PLT $\left(\times 10^{9} / \mathrm{L}\right)$ & 764.17 & 70.86 & 758.10 & 68.37 & NS \\
\hline Cortisol (ng/mL) & 7.68 & 1.52 & 16.47 & 2.77 & $P<0.01$ \\
\hline Insulin (ng/mL) & 0.53 & 0.13 & 0.84 & 0.17 & $P<0.01$ \\
\hline HOMAbeta & 2.18 & 0.98 & 2.19 & 0.75 & NS \\
\hline HOMAIR & 0.21 & 0.06 & 0.42 & 0.14 & $P<0.01$ \\
\hline QUICKI & 0.53 & 0.03 & 0.45 & 0.03 & $P<0.01$ \\
\hline
\end{tabular}

\section{DISCUSSION}

NIH test is a referent test for the evaluation of the potency of the anti-rabies vaccine. This test includes live lab mice, whose blood serves as a biologic material to examine differences in blood parameters disturbances in surviving and dead mice. NIH test is a standard test which has been used since the '70s [27]. Due to welfare $3 \mathrm{R}$ rules, there are some alternatives 
to this test [29]. Most of the vaccines are made of strains Pasteur virus (PV), Pitman-Moore (PM) and challenge virus standard (CVS). In studies of vaccine potency, CVS strain was compared with other strains of rabies virus significant in veterinary medicine. Some specifics of CVS usage have been found in the process of evaluation of vaccine potency [28]. Changes in CNS show that apoptosis is significant in the process of cell death. The more the virus is neurovirulent, the apoptosis is less expressed [18]. One of the ways of cell degeneration is excitotoxicity. This is the pathological process by which neurons are damaged and killed by the over-activation of receptors. So the brain damage in rabies is based on metabolic changes. Some studies have shown that viral RNA could be found in blood samples of infected mice. This indicates that viremia could develop during rabies infection [17].

Cases of transmission from man to man during transplantation of organs and cornea are described in the literature [19]. All of the listed could be related to the systemic presence of rabies virus in an organism. This could explain metabolic adaptations in mice that survived and did not survive NIH test.

A higher concentration of cortisol, insulin and disturbance in insulin sensitivity were found in mice that died after the application of CVS-27 during $\mathrm{NIH}$ test. That indicates stress response and insulin resistance development. Studies are mainly based on corticosterone concentrations, but newer studies show a high correlation of cortisol and corticosterone in lab mice during physiologic, acute, and chronic stress [11]. Cortisol has numerous roles in the organism. Cortisol increases the level of gluconeogenesis [4], which can be related to increased glycaemia in lab mice that died after the application of CVS-27. Earlier works showed that in the early phase of rabies, glucosuria, and hyperglycaemia could be noticed [20]. Higher glycaemia follows an increase in insulin, but it was noted that there was insulin resistance development in mice that died. In lab mice, acute stress or cortisol application can cause an increase in insulin level [1]. It has been shown that Brain-to-Pancreatic Islet Neuronal Map allows CNS to cause the increased secretory function of pancreas. That is proven by the usage of pseudorabies virus [24]. These regulations can be related to increased insulin concentration in the blood of mice that died after CVS-27 inoculation. Insulin resistance is defined as the incapability of pancreatic cells to produce insulin or inadequate tissue response to circulating insulin [6]. Insulin resistance in lab mice is related to higher HOMAIR index and lower QUICKI index [2]. Our results are in accordance with theirs. Insulin resistance is followed by greater lipolysis and ketogenesis because insulin is the only lipogenic hormone.

Other hormones, including cortisol, are lipolytic. During the NIH test in later stages, mice expressed reduced food intake and starvation that caused increased lipolysis and a decrease in glucose and insulin [14]. Higher concentrations of glucose and insulin were noted in dead mice in our research. A higher concentration of glucose and ketone bodies in CNS is found in later CNS infection stages [26]. Obtained results are in accordance with this. Same authors concluded that during RABV infection, CNS uses less glucose and insulin for metabolic processes. Changes that were noted in our study are similar to changes shown in CNS during RABV infection.

The large group of metabolites showed a smaller but still significant effect in explaining metabolic variance after CVS-27 application. The increase in $\mathrm{pH}$ of dead animals was noted, which is in accordance with keto-alkalosis development in one described case of rabies in people [7]. Alkalosis in rabies is of a respiratory type, and it is developed by hyperventilation, inspiratory spasm and deeper inspiration. That can be related to encephalitis, followed by an increase in alveolar pressure and development of pneumomediastinum [12,31]. Increased concentrations of ALT and LDH could be caused by stress [25] and more significant muscle load. RT-PCR and immunohistochemistry methods showed that wild strain of rabies virus could replicate in muscular tissue [5]. Muscle load can be related to neuromuscular irritability and spasm. RABV is replicated in muscles, so direct action of viral particles cannot be excluded [13]. Higher values of urea and creatinine could be related to protein catabolism and muscle load. Higher albumin values could be related to dehydration of the organism and great loss of water. Diabetes insipitus is developed in encephalitis syndrome [30], and it is characterized by greater water loss with decreased kidney filtration. Lactate concentrations were increased in dead mice. CSF examinations show higher lactate concentrations in mice infected with RABV, especially in later stages [21]. Higher lactate concentration could be a consequence of changes in the blood-brain barrier that develops during rabies. 
Haematological changes in rabies are mild. In our research, they are greater and can be related to cortisol and stress action [4]. MPV change can be a sign of immunologic thrombocytopenic purpura described after rabies vaccine application [10].

\section{CONCLUSIONS}

Mice that died during NIH test after applying CVS-27 expressed more significant stress (higher cortisol level). Disturbances of energy metabolism were noted (more significant catabolism of lipids and insulin resistance), changes of protein metabolism caused by muscle load (urea, creatinine, AST and LDH) and general disturbances of acid-base status (higher $\mathrm{pH}$ ) and dehydration (increased albumin) were also noted in mice that died.

This study demonstrated that PCA was capable of differentiating between died and survived mice by measuring their blood biochemical parameters. Discriminant function analysis was able to clearly identify died mice after application of CVS-27 using the biochemical parameters (cortisol, HOMA-IR, lactates, insulin, AST and $\mathrm{LDH}$ ) as input data which strongly correlates with principal component 1 .

Hematology parameters showed mild effect on metabolic parameters variability and survival outcome in mice. Disturbances in blood metabolic parameters showed an analogy with previous studies of CNS. Blood parameters can be very useful in clinicalpathological analysis in RABV infection.

\section{MANUFACTURERS}

${ }^{1}$ National Reference Laboratory for Rabies Pasteur Institute Novi Sad. Novi Sad, Serbia.

${ }^{2}$ Zentralinstitut für Versuchstierzucht GmbH. Hannover, Germany.

${ }^{3}$ Richter Pharma AG. Wels, Austria.

${ }^{4}$ Becton, Dickinson and Company. Franklin Lakes, NJ, U.S.A.

${ }^{5}$ WTW inoLab. Weilheim, Germany.

${ }^{6}$ Nihon Kohden. Tokyo, Japan.

${ }^{7}$ Biosystems S.A. Barcelona, Spain.

${ }^{8}$ Rayto Life and Analytical Sciences Co. Shenzhen, China.

${ }^{9}$ Tosoh Corporation, Scientific Instruments Division. Kaiseicho, Japan. ${ }^{10}$ SPSS - International Business Machines Corporation. Armonk, NY, USA.

Ethical approval. Experiment was conducted in accordance with the decision and authorization of the Ministry of Agriculture, Forestry and Water Management (Veterinary Administration) number 323-07-01465/2014-05-1.

Declaration of interest. The authors report no conflicts of interest. The authors alone are responsible for the content and writing of paper.

\section{REFERENCES}

1 Ahn T., Bae C.S. \& Yun C.H. 2016. Acute stress-induced changes in hormone and lipid levels in mouse plasma. Veterinarni Medicina. 61(2): 57-64.

2 Avtanski D., Pavlov V.A., Tracey K.J. \& Poretsky L. 2019. Characterization of inflammation and insulin resistance in high-fat diet-induced male C57BL/6J mouse model of obesity. Animal Models and Experimental Medicine. 2(4): 252-258.

3 Banyard A.C. \& Tordo N. 2018. Rabies pathogenesis and immunology. Revue Scientifique et Technique (International Office of Epizootics). 37(2): 323-330.

4 Belić B. \& Cincović M.R. 2015. Pathological Physiology. Novi Sad: Poljoprivredni fakultet, pp.30-39.

5 Charlton K.M., Nadin-Davis S., Casey G.A. \& Wandeler A.I. 1997. The long incubation period in rabies: delayed progression of infection in muscle at site of exposure. Acta Neuropathologica. 94(1): 73-77.

6 Cincović M.R., Đoković R., Belić B., Lakić I., Stojanac N., Stevančević O. \& Staničkov N. 2018. Insulin resistance in cows during the periparturient period. Acta Agriculturae Serbica. 23(46): 233-245.

7 Contou D., Dacheux L., Bendib I., Jolivet S., Rodriguez C., Tomberli F., de Langavant L.C., Lavenir R., Lepelletier A., Larrous F. \& Troupin C. 2015. Severe ketoalkalosis as initial presentation of imported human rabies in France. Journal of Clinical Microbiology. 53(6): 1979-1982.

8 Dietzschold B., Li J., Faber M. \& Schnell M. 2008. Concepts in the pathogenesis of rabies. Future Virology. 3(5): 481-490.

9 Fu Z.F., Weihe E., Zheng Y.M., Schäfer M.K., Sheng H., Corisdeo S., Rauscher F.J., Koprowski F. \& Dietzschold B. 1993. Differential effects of rabies and borna disease viruses on immediate-early-and late-response gene expression in brain tissues. Journal of Virology. 67(11): 6674-6681.

10 Fulbright J.M., Williams S.E. \& Pahud B.A. 2015. A case of immune thrombocytopenic purpura after rabies vaccination. Journal of Pediatric Hematology/Oncology. 37(7): e427-e428. 
11 Gong S., Miao Y.L., Jiao G.Z., Sun M.J., Li H., Lin J., Luo M.J. \& Tan J.H. 2015. Dynamics and correlation of serum cortisol and corticosterone under different physiological or stressful conditions in mice. PloS One. 10(2): p.e0117503.

12 Hemachudha T., Ugolini G., Wacharapluesadee S., Sungkarat W., Shuangshotib S. \& Laothamatas J. 2013. Human rabies: neuropathogenesis, diagnosis, and management. The Lancet Neurology. 12(5): 498-513.

13 Jackson A.C., Ye H., Phelan C.C., Ridaura-Sanz C., Zheng Q., Li Z., Wan X. \& Lopez-Corella E. 1999. Extraneural organ involvement in human rabies. Laboratory Investigation: A Journal of Technical Methods and Pathology. 79(8): 945-951.

14 Jensen T.L., Kiersgaard M.K., Sørensen D.B. \& Mikkelsen L.F. 2013. Fasting of mice: a review. Laboratory Animals. 47(4): 225-240.

15 Lewis C.E., Reising M.M., Fry A.M., Conrad S.K., Siev D., Gatewood D.M. \& Hermann J.R. 2013. Evaluation of a non-invasive, inhalational challenge method for rabies vaccine potency assay. Journal of Virological Methods. 190(1-2): 49-52.

16 Liao P.H., Hsu Y.H., Yang H.H., Wang M.H. \& Chen L.K. 2012. Involvement of extraneural tissues and upregulation of inducible nitric oxide synthase after experimental infection with rabies virus in BALB/c mice and LEW/SsN rats. Pathology International. 62(9): 619-627.

17 Lodmell D.L., Dimcheff D.E. \& Ewalt L.C. 2006. Viral RNA in the bloodstream suggests viremia occurs in clinically ill rabies-infected mice. Virus Research. 116(1-2): 114-118.

18 Mahadevan A., Suja M.S., Mani R.S. \& Shankar S.K. 2016. Perspectives in diagnosis and treatment of rabies viral encephalitis: insights from pathogenesis. Neurotherapeutics. 13(3): 477-492.

19 Maier T., Schwarting A., Mauer D., Ross R.S., Martens A., Kliem V., Wahl J., Panning M., Baumgarte S., Müller T. \& Pfefferle S. 2010. Management and outcomes after multiple corneal and solid organ transplantations from a donor infected with rabies virus. Clinical Infectious Diseases. 50(8): 1112-1119.

20 Mohamed A. \& Banerjee A. 2000. Rabies in the accident and emergency department. Emergency Medicine Journal. 17(5): 388.

21 O'Sullivan A., Willoughby R.E., Mishchuk D., Alcarraz B., Cabezas-Sanchez C., Condori R.E., David D., Encarnacion R., Fatteh N., Fernandez J. \& Franka R. 2013. Metabolomics of cerebrospinal fluid from humans treated for rabies. Journal of Proteome Research. 12(1): 481-490.

22 Overduin L.A., van Dongen J.J.M. \& Visser L.G. 2019. The cellular immune response to rabies vaccination: a systematic review. Vaccines. 7(3): 110. doi: 10.3390/vaccines7030110

23 Reinke S.N., Resch L., Maingat F., Branton W., Jackson A.C., Holt R., Slupsky C., Marrie T., Sykes B.D. \& Power C. 2013. Metagenomic and metabolomic characterization of rabies encephalitis: new insights into the treatment of an ancient disease. The Journal of Infectious Diseases. 207(9): 1451-1456.

24 Rosario W., Singh I., Wautlet A., Patterson C., Flak J., Becker T.C., Ali A., Tamarina N., Philipson L.H., Enquist L.W. \& Myers M.G. 2016. The brain-to-pancreatic islet neuronal map reveals differential glucose regulation from distinct hypothalamic regions. Diabetes. 65(9): 2711-2723.

25 Sánchez O., Arnau A., Pareja M., Poch E., Ramírez I. \& Soley M. 2002. Acute stress-induced tissue injury in mice: differences between emotional and social stress. Cell Stress \& Chaperones. 7(1): 36-46.

26 Schutsky K., Portocarrero C., Hooper D.C., Dietzschold B. \& Faber M. 2014. Limited brain metabolism changes differentiate between the progression and clearance of rabies virus. PloS One. 9(4): e87180.

27 Seligman E.B. 1973. The NIH test for potency. In: Kaplan M.M. \& Koprowski H. (Eds). Laboratory Techniques in Rabies. 3rd edn. Geneva: World Health Organization, pp.279-286.

28 Servat A., Wasniewski M. \& Cliquet F. 2019. Cross-protection of inactivated rabies vaccines for veterinary use against bat lyssaviruses Occurring in Europe. Viruses. 11(10): 936.

29 Stankov S., Obradović N., Vujin D. \& Vranješ N. 2020. Possibility of Immediate Introduction of a Single-Dose Antibody Induction Test as a Refinement of the NIH Test for Inactivated Rabies Vaccine Potency Determination. Viral Immunology. 33(5): 367-377.

30 Udwadia Z.F., Udwadia F.E., Katrak S.M., Dastur D.K., Sekhar M.A., Lall A.J., Kumta A.N. \& Sane B.H. 1989. Human rabies: clinical features, diagnosis, complications, and management. Critical Care Medicine. 17(8): 834-836. 
31 Wang W., Ni Y., Gao K., Lu Q. \& Li X. 2013. Spontaneous pneumomediastinum due to paralytic rabies. Brazilian Journal of Infectious Diseases. 17(1): 94-96.

32 Warrell D.A., Davidson N.M., Pope H.M., Bailie W.E., Lawrie J.H., Ormerod L.D., Kertesz A. \& Lewis P. 1976. Pathophysiologic studies in human rabies. The American Journal of Medicine. 60(2): 180-190.

33 Willoughby R.E. 2015. Rabies: rare human infection-common questions. Infectious Disease Clinics. 29(4): 637-650.

34 Willoughby R.E., Opladen T., Maier T., Rhead W., Schmiedel S., Hoyer J., Drosten C., Rupprecht C., Hyland K. \& Hoffmann G.F. 2009. Tetrahydrobiopterin deficiency in human rabies. Journal of Inherited Metabolic Disease. 32(1): 65-72. 